\title{
Effects of Reduced in Utero and Post-Weaning Nutrition on Glucose Clearance Measures and Serum Metabolites
}

\author{
Richard Waterman*, Mark Petersen, Thomas Geary, Lance Vermeire \\ USDA-ARS, Fort Keogh Livestock and Range Research Laboratory, Miles City, MT, USA \\ Email: *richard.waterman@ars.usda.gov
}

How to cite this paper: Waterman, R., Petersen, M., Geary, T. and Vermeire, L. (2018) Effects of Reduced in Utero and Post-Weaning Nutrition on Glucose Clearance Measures and Serum Metabolites. Agricultural Sciences, 9, 947-957. https://doi.org/10.4236/as.2018.98066

Received: May 30, 2018

Accepted: August 12, 2018

Published: August 15, 2018

Copyright (c) 2018 by authors and Scientific Research Publishing Inc. This work is licensed under the Creative Commons Attribution International License (CC BY 4.0).

http://creativecommons.org/licenses/by/4.0/

\section{(c) () Open Access}

\begin{abstract}
Lowering production costs while maintaining an optimal level of production is important to producers in extensive environments. Efforts that strive to match the environment to the nutritional requirements of the grazing animal will substantially improve economic returns to the producer. Therefore, a 3-yr study was implemented that evaluated glucose clearance and serum metabolites in primiparous beef heifers $(n=48 ; 16 / y r)$ from two different feeding regimes. Serum metabolites and glucose clearance measures were analyzed by fitting a repeated measure mixed model using the MIXED procedure of SAS 9.4 (SAS Inst., Inc., Cary, NC). Heifers dams received adequate 1.8 (ADEQ) or marginal 1.2 (MARG) kg/d winter supplementation for approximately $80 \mathrm{~d}$ prior to parturition and their heifer calves were then randomly assigned to heifer development treatments that provided ad-libitum (AL) or $80 \%$ of ad-libitum (LAL) feed post weaning. Heifers that received the AL treatment during the developmental period were then assigned the $1.8 \mathrm{~kg} / \mathrm{d}$ winter supplementation for life, whereas heifers that received the LAL treatment during development were assigned the $1.2 \mathrm{~kg} / \mathrm{d}$ winter supplementation for life. Peak glucose concentrations in response to a bolus dose of glucose changed in magnitude between ADEQ and MARG in utero treatments and decreased further removed from parturition $(\mathrm{P}=0.05)$. However, these changes did not manifest along with other glucose clearance measures $(\mathrm{P}>$ 0.17 ) indicating that regardless of in utero treatment or heifer development treatment the reduction in feed input did not greatly influence glucose clearance measures or baseline serum metabolites throughout postpartum, first parity period.
\end{abstract}

\section{Keywords}

Heifer Development, Glucose, Primiparous Beef Cow 


\section{Introduction}

Extensive livestock production challenges producers to match available resources to requirements of livestock being raised in a given environment. Livestock producers in arid and semi-arid environments must adapt to current environmental conditions to maintain a sustainable level of animal production and provide economic security to the livestock operation. Producers are often faced with making decisions to either liquidate cattle or purchase additional feedstuffs with the latter resulting in increased production cost and threatening the sustainability of the livestock operation in the future. The challenge for researchers is to develop management accepted approaches that result in minimal financial liability. Current research efforts are being implemented to optimize nutrient utilization while not maximizing or meeting intake potential of grazing livestock yet optimizing the use of dietary nutrients to support serum metabolites going towards developing tissues. By not maximizing dietary intake but reducing the amount of supplementary harvested feeds during times of diminished forage quality the cost of production can be reduced, and the focus then shifts to the necessity of nutrient use by the animal and maintaining production goals.

In Northern Great Plains, USA, as well as, other similar arid and semi-arid environments harvested feedstuffs are supplemented during the periods when grazing livestock is consuming poor quality and/or an insufficient quantity of forage is available. This feeding paradigm may ultimately mask or result in higher production cost in future offspring. If culling strategies account for up to $20 \%$ of bred females and a producer retains $55 \%$ of weaned females most of the production costs to develop those heifers is associated with feed [1]. While many approaches have been used to minimize the cost associated with the development of replacement heifers, such as altering timing of prepubertal growth [2] [3] there may be detrimental impacts on onset of puberty [2]. Yambayamba et al., [4] conducted a study evaluating physiological and metabolic changes associated with dietary restriction and subsequent realimentation on compensatory gain. Authors conclude that ruminants more severely restricted have greater compensatory gain upon realimentation due to greater efficiency of converting dietary nutrients to maternal tissue. Building upon these concepts, under the current paradigm the approach is to allow animals to more naturally adapt to the environment that they're being raised in. In this effort, less emphasis is on maximizing intake, rather the focus is shifted to supplying nutrients in reduced amounts and allowing the grazing ruminant to adapt and become more efficient at utilizing dietary feedstuffs. In a companion study, Waterman et al., [5] observed no determinantal impact in first parity milk yield when nutritional inputs were lessened during in utero and post-weaning heifer development. The present study evaluates glucose clearance and serum metabolites (urea $\mathrm{N}$, non-esterified fatty acids, and $\beta$-hydroxybutyrate) throughout first parity lactation that may be influenced by nutritional regimens implemented during in utero and post weaning development. Thus, our objective was to evaluate effects 
of the previously established nutritional paradigms (in utero and post weaning) on glucose clearance and certain serum metabolite profiles.

\section{Material and Methods}

\subsection{Study Location and Environment}

This study was conducted at the USDA-ARS Fort Keogh Livestock and Range Research Laboratory (LARRL) located approximately $1.6 \mathrm{~km}$ west of Miles City, MT $\left(46^{\circ} 22^{\prime} \mathrm{N} 105^{\circ} 5^{\prime} \mathrm{W}\right)$ from April 2009 through August 2011. LARRL Institutional Animal Care and Use Committee approved all animal handling and experimental procedures used in this current study.

The LARRL encompasses 22,500 ha and has an average elevation of $730 \mathrm{~m}$. Average daily temperatures range from $-12^{\circ} \mathrm{C}$ in January to $24^{\circ} \mathrm{C}$ in July with daily maximum temperatures occasionally greater than $37^{\circ} \mathrm{C}$ during summer and daily minimum temperature occasionally dropping less than $-40^{\circ} \mathrm{C}$ during winter. Winter mean temperatures during the study were similar to the long-term average [5]. Predominant grasses at this site include grama (Bouteloua), needle grass (Hesperostipa), and wheatgrass (Pascopyrum; Kuchler, 1964) [6]. Average standing crop of forage produced annually at the study site is $870 \pm$ $14 \mathrm{~kg} / \mathrm{ha}$ [7]. Stocking rate was $1.27 \mathrm{ha} / \mathrm{AUM}$ and the quantity of forage available in the 53.8 ha pasture during $128 \mathrm{~d}$ that primiparous cows were on trial was in excess of cattle needs. More specific information on forage characteristics and nutritional regime can be obtained in our companion study [5].

\subsection{Herd Management}

Dams of heifers used in this study come from a stable composite population (1/2 Red Angus, 1/4 Charolais, 1/4 Tarentaise) described by Newman et al., [8] [9] and primiparous cows were nursing steer calves in this study. Management of this population is such that dams receive a lifetime treatment of either adequate (ADEQ) or marginal (MARG) winter supplementation consisting of alfalfa hay $(1.8$ or $1.2 \mathrm{~kg} / \mathrm{d}$ ) for $80 \mathrm{~d}$ prior to parturition [10]. Briefly, at weaning heifer calves are removed from their dams, relocated to dry lots, and developed in pens that facilitate individual feeding using Calan gates (American Calan, Northwood, NH). At weaning, a 140-d developmental period is initiated where diets consisted of either ad-libitum (AL) or $80 \%$ of ad-libitum (LAL-less than ad-libitum). Diets for LAL heifers are adjusted every 28 -d using the following formula:

$\mathrm{LAL}=0.80 \times$ mean body weight $(\mathrm{BW})$ of restricted $/$ mean $\mathrm{BW}$ control $\times$ mean daily feed intake (as fed basis) of controls over the 28-d period.

Just prior to breeding, after the 140-d developmental period, heifers were commingled and managed similarly through their first breeding season. At time of pregnancy conformation, the now primiparous were assigned to lifetime fall/winter treatments. The now primiparous cows, which during heifer development and had received the all treatments, were now assigned the ADEQ $(1.8 \mathrm{~kg} / \mathrm{d})$ 
fall/winter lifetime treatment and the primiparous cows that received the LAL development treatment were assigned the MARG $(1.2 \mathrm{~kg} / \mathrm{d})$ fall/winter lifetime treatment. Prior to calving, primiparous cows were commingled and managed similarly throughout the year until fall/winter treatments were once again initiated. Description of experimental design and herd management has previously been reported [11] [12] [13].

\subsection{Experimental Animals}

Throughout this 3-yr study, sixteen primiparous cows nursing steer calves were selected from the previously described population. Primiparous cows were selected to provide equal subclass representation for in utero nutrition for $80 \mathrm{~d}$ prior to parturition (ADEQ and MARG, $\mathrm{n}=24$ respectively) and post-weaning heifer development treatment ( $\mathrm{AL}$ and LAL, $\mathrm{n}=25$ and 23, respectively) and for having steer calves of similar age.

\subsection{Measurements}

Serum collection began approximately $27 \mathrm{~d}$ (earliest date to acquire selection criteria previously mentioned) after parturition (avg. April 16 each year) and continued at $7 \mathrm{~d}$ intervals throughout the duration of the study. Serum samples were collected via coccygeal venipuncture using $9 \mathrm{~mL}$ serum separator tubes (Corvac $^{\mathrm{TM}}$, Tyco Healthcare Group LP, Mansfield, MA, USA). Samples were placed on ice and transported to the laboratory where they were centrifuged at $1500 \times \mathrm{g}$ for $30 \mathrm{~min}$ and stored at $-20^{\circ} \mathrm{C}$ until analysis.

In addition, every $14 \mathrm{~d}$ a glucose clearance test (GCT) was implemented following parturition. On the day of the GCT, at $0800 \mathrm{~h}$, cows were gathered and trailed to a cattle-working facility, and fitted with an indwelling jugular catheter. Immediately following catheterization, cows were walked, in a low stress manner, to an individual stall located approximately $45 \mathrm{~m}$ adjacent to chute where indwelling jugular catheterization occurred. Technicians began GCT once cows were stalled. There was no access to feed or water during the GCT. For the GCT, a $50 \%$ (wt/vol) dextrose solution was infused through the catheter at $0.50 \mathrm{~mL} / \mathrm{kg}$ BW (250 mg glucose/kg BW) using 60-mL syringes. Blood samples were collected into syringes via jugular indwelling catheter at $-1,0,3,6,9,12,15,20,40$, $60,80,100,120,140,160$, and 180 min relative to glucose infusion (infusion was immediately after obtaining the -1 and 0 min blood sample). During each collection time $2 \mathrm{~mL}$ of blood was initially drawn and discarded to remove saline $(0.9 \% \mathrm{NaCl})$ from the catheter. Blood was then subsequently drawn and transferred from syringes into serum separator tubes $(9 \mathrm{ml}$ draw serum separator tubes; Corvac ${ }^{\mathrm{TM}}$, Tyco Healthcare Group LP, Mansfield, MA, USA). A $5 \mathrm{~mL}$ saline flush was then pushed through the catheter and saline syringe remained attached to the catheter until subsequent collection time. Samples were allowed to coagulate on ice, and serum was harvested after centrifugation at $1500 \times \mathrm{g}$ for $30 \mathrm{~min}$ and stored at $-20^{\circ} \mathrm{C}$ until analysis. 
To evaluate if serum metabolite concentrations were influenced by nutritional regime baseline concentrations were evaluated for glucose, urea-N, NEFA, and ketones ( $\beta$-hydroxybutyrate) using weekly blood samples and the -1 and 0 pre-infusion samples prior to the bi weekly GCT measures.

All serum metabolite concentrations were analyzed in duplicate aliquots using commercially available kits to measure glucose via the glucose oxidase method (Kit TR15321; Thermo Electron Corp., Waltham, MA, USA; endpoint with a intraassay $\mathrm{CV}$ of $2.2 \%$ and interassay $\mathrm{CV}$ of $3.9 \%$ ), urea-N via the urease method (Kit TR12321; Thermo Electron Corp., Waltham, MA, USA; endpoint with a intraassay $\mathrm{CV}$ of $2.4 \%$ and interassay $\mathrm{CV}$ of $10.9 \%$ ), and NEFA (ACS-ACOD method; Wako Chemicals USA, Inc., Richmond, VA, USA, endpoint with an intraassay $\mathrm{CV}$ of $3.9 \%$ and interassay $\mathrm{CV}$ of $8.2 \%$ ). A handheld ketone sensor (MediSence ${ }^{\circledast}$; Precision Xtra ${ }^{\mathrm{TM}}$; Abbott laboratories, Abbott Park, IL 60064, USA) was used to measure serum $\beta$-hydroxybutyrate [14].

\subsection{Statistical Analysis}

Glucose half-life was estimated for each animal by regression of the logarithmic transformed metabolite concentrations over time [15] [16]. Area under the curve (AUC) was determined for glucose concentrations using trapezoidal summation. Serum metabolites and GCT measures were analyzed by fitting a repeated measure mixed model using the MIXED procedure of SAS 9.4 (SAS Inst., Inc., Cary, NC). The model included fixed effects of in utero nutrition, and post-weaning heifer development treatments, day of measurement and all interactions for fixed effects. Animal and year effects were fitted as random effects. The covariance of the repeated measures factor was modeled with the first order auto regressive covariance structure $\mathrm{AR}(1)$. Covariates used in the analysis of serum metabolites and GCT measures included calf birth weight and days in milk. Statistical significance was set at $\mathrm{P} \leq 0.05$. The Bonferroni method was used to adjust $\mathrm{P}$-values for multiple comparisons. The model included fixed effects of in utero nutrition, and post-weaning heifer development treatments, year and all interactions. Data were fitted to the following statistical model:

$$
\begin{aligned}
y_{i j k l m}= & \mu+A_{i(j k l)}+\gamma_{l}+\alpha_{j}+\beta_{k}+\rho_{m}+\alpha \beta_{j k}+\alpha \rho_{j m} \\
& +\beta \rho_{k m}+\alpha \beta \rho_{j k m}+b w_{i j k l}+\operatorname{dim}_{i j k l}+e_{i j k l m}
\end{aligned}
$$

where $y$ is the observation, $\mu$ is the overall mean, $A_{i(j k l)}$ the ith animal effect within each treatment and year, $\gamma_{l}$ the $t$ th year effect (random effect), $\alpha_{j}$ the $j$ th $i n$ utero treatment, $\beta_{k}$ the $k$ th post weaning treatments, $\rho_{m}$ the $m$ th day effect (repeated measures factor and is a fixed effect), and $e$ the associated error. The denominator degrees of freedom for significant testing were adjusted using the Kenward-Rodger approximation. The REPEATED statement included collection date with the subject cow by (in utero $\times$ heifer development treatment) using an autoregressive covariance structure. Covariates used in the analysis of serum metabolites and GCT measures included calf birth weight, and days in milk. Sta- 
tistical significance was set at $\mathrm{P} \leq 0.05$. The Bonferroni method was used to adjust P-values for multiple comparisons [17].

\section{Results and Discussion}

\section{In Utero and Post Weaning Heifer Development Serum Metabo- lites and GCT Measures}

Peak glucose concentration following the bolus dose resulted in a in utero $\times$ week $(\mathrm{P}=0.05$, Figure 1$)$. While there were differences in magnitude for primiparous cows to have different peak glucose concentrations following bolus infusion of glucose across weeks following parturition (i.e., during first parity lactation) in regards to in utero treatment their dam received. Peak glucose concentration did decline as weeks progressed further away from parturition and the magnitude between ADEQ and MARG in utero treatments converged closer together. This may indicate that early clearance of glucose from peripheral blood supply may favor MARG in utero treated heifers over those that received ADEQ. Previous studies evaluating glucose clearance in this management regime observed no difference in peak glucose concentrations immediately following heifer development or again in early gestation during their second pregnancy [13].

Serum NEFA concentrations had observed changes in magnitude from weekly serum samples for in utero $\times$ week $(\mathrm{P}<0.01$, Figure 2$)$. Serum NEFA concentrations provide evidence of amount of fatty acids either coming from lipolysis to support an energy need or from the diet going towards lipogenesis for energy storage. Serum NEFA concentrations early in postpartum may suggest that MARG in utero treated heifers relied on adipose tissue to meet energy needs but quickly returned to similar concentrations as those observed for ADEQ in utero supplemented cows. In general serum NEFA concentrations declined as the



Figure 1. Peak glucose concentrations $(\mathrm{mg} / 100 \mathrm{~mL}$; mean $\pm \mathrm{SEM})$ for a in utero nutrition (adequate (ADEQ) or marginal (MARG) winter supplementation consisting of alfalfa hay $(1.8$ or $1.2 \mathrm{~kg} / \mathrm{d})$ for $80 \mathrm{~d}$ prior to parturition $) \times$ week interaction $(\mathrm{P}=0.05)$. 


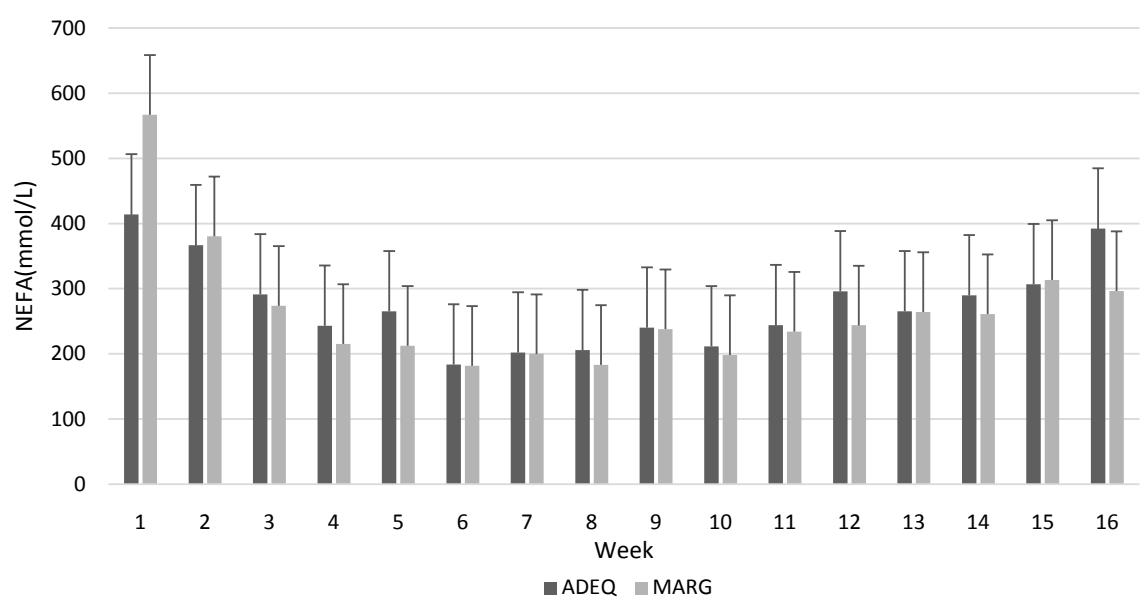

Figure 2. Serum NEFA weekly concentrations (mmol/L; mean \pm SEM) for a in utero nutrition (adequate (ADEQ) or marginal (MARG) winter supplementation consisting of alfalfa hay $(1.8$ or $1.2 \mathrm{~kg} / \mathrm{d})$ for $80 \mathrm{~d}$ prior to parturition $) \times$ week interaction $(\mathrm{P} \leq 0.01)$.

post-partum period progressed until later weeks when forage quality was known to diminish as forges senesced [5]. Results suggest that serum NEFA concentrations increase in later weeks when forage quality is diminished and more prominently used for an energy need. This data would also suggest that ADEQ in utero treated cows may be more reliant on these energy stores than MARG treated cows in periods when forage quality is diminished. Physiological conditions of the ruminant allow for communication between adipose tissue and the liver, while the volatile fatty acid butyrate, fermentation product from the rumen, is the primary source for ketone formation in the liver, when animal is in moderate to severe energy negative energy balance. If or when butyrate supply is diminished NEFA provide the carbon for ketones in the liver [18].

Bi-weekly GCT measures and weekly evaluation of serum metabolites are described in Table 1. Data from these measures strongly suggest that first parity cows that received ADEQ and MARG in utero treatments and subsequently received AL or LAL development treatments have very similar post-partum responses when subjected to bi-weekly GCT and from weekly serum metabolite profiles.

The strongest response observed was across weeks or as cows progressed further away from parturition (Table 2). Glucose disappearance (\%/min), increased $(\mathrm{P}<0.01)$ as days in lactation increased and glucose AUC diminished. Both of these measures indicate that regardless in utero or development treatment all first parity cows responded similarly. Baseline glucose, and urea $\mathrm{N}$ concentrations declined $(\mathrm{P}<0.01)$ across weeks as cows became more removed from partition, whereas, $\beta$-hydroxybutyrate concentrations increased $(\mathrm{P}<0.01)$. These changes in baseline metabolites is most likely attributed to changes in forage quality, but again all first parity cows responded similarly regardless of in utero or development treatment. 
Table 1. Least square means for serum metabolites and glucose clearance measures on in utero nutrition (Cow) and post-weaning heifer development (Heifer) throughout first parity lactation.

\begin{tabular}{|c|c|c|c|c|c|c|c|c|c|}
\hline \multirow[b]{2}{*}{ Items } & \multicolumn{2}{|c|}{ In utero $\mathrm{TRT}^{*}$} & \multirow[b]{2}{*}{ SEM } & \multicolumn{2}{|c|}{ Heifer $\mathrm{TRT}^{\dagger}$} & \multirow[b]{2}{*}{ SEM } & \multicolumn{3}{|c|}{ P-Value } \\
\hline & ADEQ & MARG & & $\mathrm{AL}$ & LAL & & $\begin{array}{c}\text { In utero } \\
\text { TRT }\end{array}$ & $\begin{array}{c}\text { Heifer } \\
\text { TRT }\end{array}$ & $\begin{array}{c}\text { In utero } \times \\
\text { Heifer TRT }\end{array}$ \\
\hline $\mathrm{n}=$ & 24 & 24 & & 25 & 23 & & & & \\
\hline \multicolumn{10}{|l|}{ Glucose Tolerance test } \\
\hline Peak Glucose (mg/100 mL) & 203 & 201 & 2.27 & 202 & 203 & 2.26 & 0.52 & 0.51 & 0.51 \\
\hline Peak Time (min) & 3.5 & 3.4 & 0.12 & 3.5 & 3.4 & 0.12 & 0.58 & 0.75 & 0.17 \\
\hline Glucose disappearance (\%/min) & 0.5 & 0.5 & 0.01 & 0.5 & 0.5 & 0.01 & 0.36 & 0.14 & 0.79 \\
\hline Glucose $\mathrm{t} 1 / 2(\mathrm{~min})$ & 66.7 & 77.3 & 5.45 & 66.7 & 77.3 & 5.43 & 0.17 & 0.16 & 0.46 \\
\hline Glucose AUC $((\mathrm{mg} / \mathrm{mL}) \times 180 \mathrm{~min})$ & 16,585 & 17,502 & 595.3 & 16,564 & 17,522 & 592.1 & 0.25 & 0.28 & 0.51 \\
\hline \multicolumn{10}{|l|}{ Baseline metabolites } \\
\hline Glucose (mg/100 mL) & 72.2 & 70.1 & 1.62 & 70.7 & 71.7 & 1.64 & 0.36 & 0.65 & 0.57 \\
\hline Urea N (mg/100 ml) & 9.3 & 9.7 & 0.26 & 9.5 & 9.6 & 0.27 & 0.28 & 0.72 & 0.15 \\
\hline $\mathrm{NEFA}(\mathrm{mmol} / \mathrm{L})$ & 276 & 266 & 9.8 & 271 & 272 & 9.8 & 0.48 & 0.92 & 0.56 \\
\hline$\beta$-hydroxybutyrate $(\mathrm{mg} / 100 \mathrm{~mL})$ & 0.21 & 0.25 & 0.014 & 0.24 & 0.22 & 0.014 & 0.02 & 0.28 & 0.54 \\
\hline
\end{tabular}

${ }^{*}$ Cows whom received in utero nutrition of adequate (ADEQ; $1.8 \mathrm{~kg} / \mathrm{d}$ ) or marginal (MARG; $1.2 \mathrm{~kg} / \mathrm{d}$ ) levels of winter supplement. ${ }^{\dagger}$ Comparison of heifers fed ad-libitum (AL) or $80 \%$ of ad-libitum fed (LAL; adjusted to a common BW) for 140-d post-weaning and fed the equivalent of either $1.8 \mathrm{~kg} / \mathrm{d}$ (AL) or 1.2 $\mathrm{kg} / \mathrm{d}$ (LAL) supplement during the winter preceding calving.

In conclusion, an inutero nutrition effect $x$ week, when dams received supplementation during the last $80 \mathrm{~d}$ of gestation was observed for peak glucose concentration following glucose clearance test and for peripheral concentrations of non-esterified fatty acids for primiparous first parity beef cows, whereas no other significant measures for glucose clearance or weekly metabolites were observed. This data suggests that reduction in supplemented feed during the in utero treatment period and the designed $20 \%$ reduction in harvested feed input during post-weaning development (on a common body weight basis) resulted in similar responses in glucose clearance measures and serum metabolite profiles compared to their counterpart which received greater amounts of. In fact, the reduction in feed during heifer development ultimately resulted in a $27 \%$ decrease in overall feed input for heifers developed in the LAL group. In other words, developing heifers with ad libitum intake compared to heifers developed at $20 \%$ less feed results in similar first parity glucose clearance measures and serum metabolite profiles. This data along with previous research conducted within this management regime not only indicate similar biological responses but an approach to decrease production cost and maintain an optimal level of production for producers. 
Table 2. Bi-weekly glucose clearance measures and weekly serum metabolite concentrations for cows whom received in utero nutrition of adequate (ADEQ; $1.8 \mathrm{~kg} / \mathrm{d}$ ) or marginal (MARG; $1.2 \mathrm{~kg} / \mathrm{d}$ ) levels of winter supplement and developed as heifers fed ad-libitum (AL) or $80 \%$ of ad-libitum fed (LAL; adjusted to a common BW) for 140 -d post-weaning and fed the equivalent of either $1.8 \mathrm{~kg} / \mathrm{d}(\mathrm{AL})$ or $1.2 \mathrm{~kg} / \mathrm{d}(\mathrm{LAL})$ supplement during the winter preceding calving.

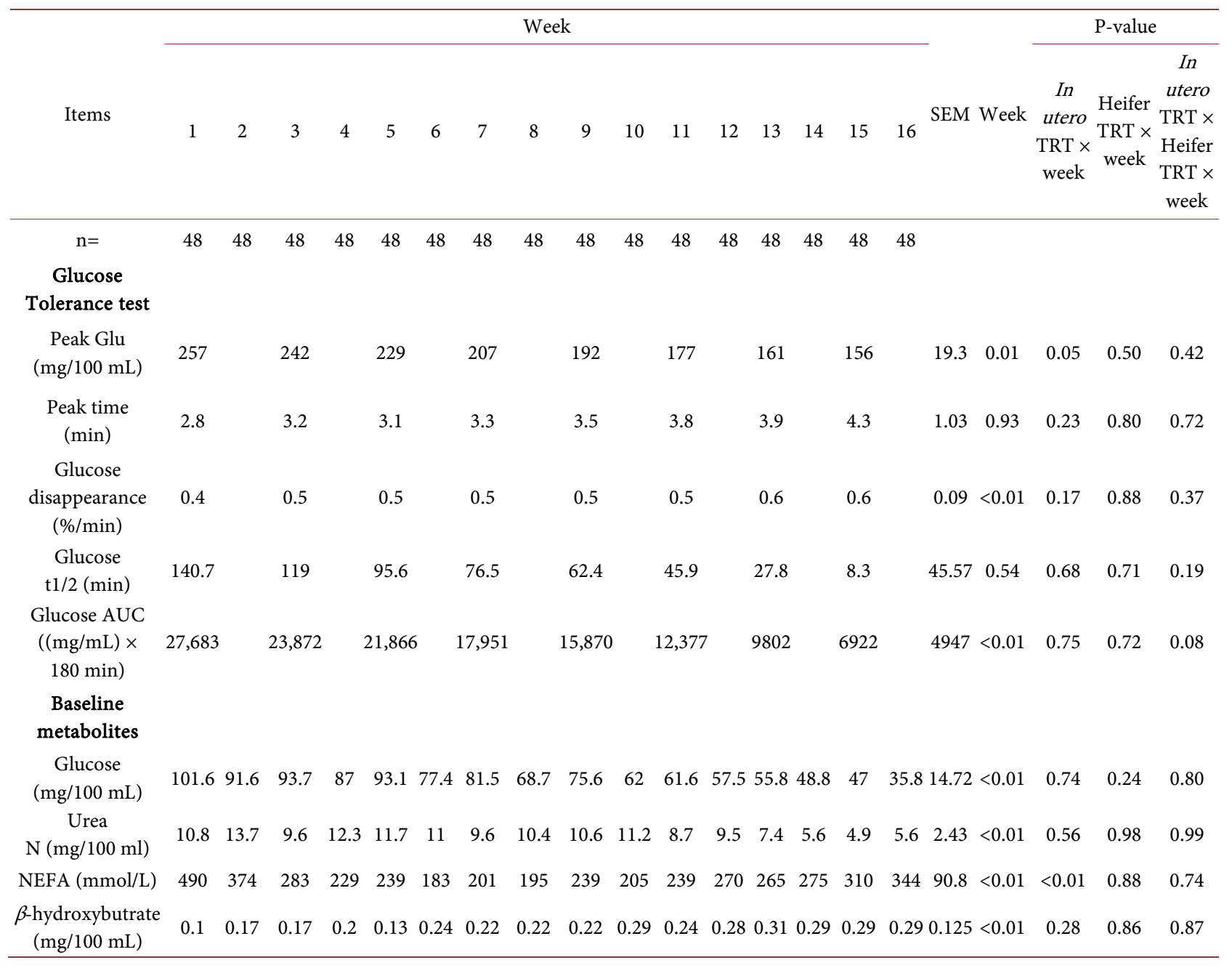

\section{Acknowledgements}

USDA-ARS is an equal opportunity/affirmative action employer and all agency services are available without discrimination. Mention of a proprietary product does not constitute a guarantee or warranty of the product by USDA or the authors and does not imply its approval to the exclusion of other products that may be also suitable. The authors gratefully acknowledge Susan Reil, Whisper Kelly, Brooke Shipp, Sheryl Murphy, Sue Bellows, Dustin Strong, Valarie Ujazdowski, Lindsey Cook, R. J. Hubbard, Dennis Logan, Tom Mott, and Brad Eik for their technical assistance.

\section{Conflicts of Interest}

The authors declare no conflicts of interest regarding the publication of this paper. 


\section{References}

[1] Freetly, H.C., Ferrell, C.L. and Jenkins, T.G. (2001) Production Performance of Beef Cows Raised on Three Different Nutritionally Controlled Heifer Development Programs. Journal of Animal Science, 79, 819-826. https://doi.org/10.2527/2001.794819x

[2] Lynch, J.M., et al. (1997) Influence of Timing of Gain on Growth and Reproductive Performance of Beef Replacement Heifers. Journal of Animal Science, 75, 1715-1722. https://doi.org/10.2527/1997.7571715x

[3] Clanton, D.C., Jones, L.E. and England. M.E. (1983) Effect of Rate and Time of Gain after Weaning on the Development of Replacement Beef Heifers. Journal of Animal Science, 56, 280-285. https://doi.org/10.2527/jas1983.562280x

[4] Yambayamba, E.S., Price, M.A. and Foxcroft. G.R. (1996) Hormonal Status, Metabolic Changes, and Resting Metabolic Rate in Beef Heifers Undergoing Compensatory Growth. Journal of Animal Science, 74, 57-69. https://doi.org/10.2527/1996.74157x

[5] Waterman, R.C., et al. (2017) Effects of Reduced in Utero and Post-Weaning Nutrition on Milk Yield and Composition in Primiparous Beef Cows. Animal, 11, 84-90. https://doi.org/10.1017/S1751731116001257

[6] Küchler, A.W. (1964) Potential Natural Vegetation of the Coterminous United States. American Geographical Society, New York, NY.

[7] Grings, E.E., et al. (2005) Calving System and Weaning Age Effects on Cow and Preweaning Calf Performance in the Northern Great Plains. Journal of Animal Science, 83, 2671-2683. https://doi.org/10.2527/2005.83112671x

[8] Newman, S., et al. (1993) Fixed Effects in the Formation of a Composite Line of Beef Cattle: I. Experimental Design and Reproductive Performance. Journal of Animal Science, 71, 2026-2032. https://doi.org/10.2527/1993.7182026x

[9] Newman, S., et al. (1993) Fixed Effects in the Formation of a Composite Line of Beef Cattle: II. Pre- and Postweaning Growth and Carcass Composition. Journal of Animal Science, 71, 2033-2039. https://doi.org/10.2527/1993.7182033x

[10] Roberts, A.J., et al. (2010) Level of Maternal Winter Supplement and Feed Restriction during Postweaning Developmnet Influences Circulating Concentrations of IGF-I in Heifers during the Peripartum and Rebreeding Period. Proceeding-American Society of Animal Science, Laramie, 24-26 June 2008, 194-196.

[11] Roberts, A.J., Geary, T.W., Grings. E.E., Waterman. R.C. and MacNeil, M.D. (2009) Reproductive Performance of Heifers Offered ad Libitum or Restricted Access to Feed for a 140-d Period after Weaning. Journal of Animal Science, 87, 3043-3052. https://doi.org/10.2527/jas.2008-1476

[12] Roberts, A.J., Paisley, S.I., Geary, T.W., Grings, E.E., Waterman, R.C. and MacNeil, M.D. (2007) Effects of Restricted Feeding of Beef Heifers during the Postweaning Period on Growth, Efficiency, and Ultrasound Carcass Characteristics. Journal of Animal Science, 85, 2740-2745. https://doi.org/10.2527/jas.2007-0141

[13] Waterman, R.C., et al. (2011) Effect of Reduced Heifer Nutrition during in Utero and Post Weaning Development on Glucose and Acetate Kinetics. British Journal of Nutrition, 106, 1702-1712. https://doi.org/10.1017/S0007114511002224

[14] Byrne, H.A., Tieszen, K.L., Hollis, S., Dornan, T.L. and New, J.P. (2000) Evaluation of an Electrochemical Sensor for Measuring Blood Ketones. Diabetes Care, 23, 500-503. https://doi.org/10.2337/diacare.23.4.500 
[15] Kaneko, J.J. (1989) Clinical Biochemistry of Domestic Animals. 4th Edition, Academic Press, San Diego, CA.

[16] Regnault, T.R., et al. (2004) Glucose-Stimulated Insulin Response in Pregnant Sheep Following Acute Suppression of Plasma Non-Esterified Fatty Acid Concentrations. Reproductive Biology and Endocrinology, 2, 64-73.

https://doi.org/10.1186/1477-7827-2-64

[17] SAS Institute (2004) SAS/Stat 9.1 User's Guide. SAS Institute Inc., Cary, NC.

[18] Zammit, V. (1990) Ketogenesis in the Liver of Ruminants-Adaptations to a Challenge. The Journal of Agricultural Science, 115, 155-162.

https://doi.org/10.1017/S0021859600075080 